\title{
Alunos com deficiência matriculados em escolas públicas de nível fundamental: algumas considerações
}

\section{Pupils with deficiency registered in Basic Level of Public Schools: some considerations}

\author{
Andrea de Aguiar Kasper* \\ Márcia do Valle Pereira Loch** \\ Vera Lúcia Duarte do Valle Pereira***
}

\begin{abstract}
RESUMO
Este artigo pretende mostrar os números referentes aos alunos com deficiências incluídos nas escolas públicas de ensino fundamental, no Brasil e no estado de Santa Catarina. Os dados apresentados são, na grande maioria, os levantados por instituições nacionais como o INEP e o IBGE, mas não se limitam a tais informações. Esses dados demonstram a realidade das escolas brasileiras e o nível econômico e sociocultural de seus alunos, além de fornecer dados sobre a inclusão de alunos com deficiência, assunto explorado pelo artigo.

Palavras-chave: inclusão escolar, censo escolar, ensino fundamental, crianças com deficiências.
\end{abstract}

\footnotetext{
ABSTRACT

This article intends to show the referring numbers to the included pupils with deficiencies in the public schools of Basic Education, in Brazil and the State of Santa Catarina. The presented data is, in great majority, the raised ones for National Institutions as the INEP and the IBGE, but they

*Universidade Federal de Santa Catarina. E-mail: akasper@deps.ufsc.br.

** Universidade Federal de Santa Catarina. E-mail: marloch@matrix.com.br.

*** Universidade Federal de Santa Catarina. E-mail: vpereira@deps.ufsc.br.
} 
are not limited to such information. This data demonstrates the reality of the Brazilian schools and the economic and partner-cultural level of its pupils. The article also explores the subject of inclusion of pupils with deficiency.

Key words: School Inclusion, School Census, Basic Education, Children with Deficiencies.

\section{Introdução}

O Censo Escolar é um importante levantamento estatístico-educacional de âmbito nacional realizado, anualmente, pelo Instituto Nacional de Estudos e Pesquisas Educacionais Anísio Teixeira (INEP). Os dados demonstram informações relevantes sobre os estabelecimentos escolares, as turmas e o rendimento escolar, informações sobre a movimentação escolar e o acesso ao transporte, por exemplo. O seu papel não é o de meramente aferir o número de matrículas na rede de ensino, mas fornecer informações importantes para a transferência de recursos aos estados e aos municípios, bem como para os programas do governo federal de apoio ao desenvolvimento da educação básica no Brasil, "tais como o FUNDEF, o Livro Didático, a Biblioteca Escola e a Alimentação Escolar (INEP, 2005)". .

Além dessas informações, com esse levantamento é possível conhecer os números da evolução das matrículas dos alunos que possuem deficiências. As informações referem-se aos estudantes tanto da rede especial de ensino como daqueles que estão incluídos na rede de escolas regulares, sejam elas públicas ou privadas.

As informações do Censo Escolar, elaborado anualmente pelo INEP, demonstram que desde 1998 existe uma tendência de queda das matrículas dos alunos no ensino fundamental, sendo uma das prováveis causas deste acontecimento a nova visão proposta pela Lei de Diretrizes e Bases da Educação Nacional (LDBEN) sobre avaliação e reprovação. As escolas passaram a adotar o sistema de ciclos, o que ajudou a corrigir o fluxo de alunos; ou seja, além das novas crianças que ingressavam na rede, havia aquelas que repetiam diversas vezes, deixando o número de matrículas sempre muito alto. Outro fator colocado diz respeito à redução da população que também contribuiu para a queda das matrículas, pois a demanda de crianças entre 7 e 14 anos tornou-se menor.

${ }^{1}$ Matéria publicada no site < http://www.inep.gov.br/imprensa/noticias/censo/escolar/ news05_10.htm.> Acesso em 05/11/2005. 
Em relação ao número de crianças e de adolescentes com deficiências matriculados em escolas no nível fundamental é constatado a cada ano um aumento, de acordo com dados do INEP em 2005. O que se percebe é que nos anos de 2003, 2004 e 2005 houve um avanço significativo das matrículas desses alunos, sendo que esse avanço demonstra a necessidade urgente de providências quanto à inclusão das crianças com deficiência nas escolas regulares e, principalmente, de preparar estas escolas, pedagogicamente, espacial e organizacionalmente, para inclusão real das crianças.

Dessa maneira, o presente artigo pretende traçar um panorama atual com relação às deficiências no contexto da escola pública brasileira, mais precisamente em relação às matrículas de alunos com deficiências no Brasil, em escolas regulares de Ensino Fundamental. Tem-se com isso a possibilidade de demonstrar, por meio dos dados, a evolução do acesso desses alunos no sistema de ensino regular nacional. $\mathrm{O}$ artigo apresenta um breve relato de dados levantados por instituições nacionais como o IBGE e o INEP, mas não se limita a estes, dando ênfase a considerações relativas ao estado de Santa Catarina. Após a apresentação dos dados realiza-se uma análise da situação atual em relação à inclusão.

\section{Números da deficiência no Brasil}

Dos mais de 500 milhões de pessoas que possuem alguma deficiência (mental, física ou sensorial) no mundo, muitos convivem com limitações e são obrigados a viver em condições desfavoráveis. Desse montante, 140 milhões são crianças (UNICEF, 2005), que, juntamente com os adultos, sobrevivem em situações marcadas pela segregação e pela degradação.

A maioria das referências quanto ao número de pessoas com deficiência existentes em uma determinada cidade ou região cita a estimativa de $10 \%$ da população geral, e indica como fonte dessa estimativa a Organização Mundial de Saúde (OMS) ou a Organizações das Nações Unidas (ONU) (SASSAKI, 1998). Para os países em desenvolvimento, essa estimativa é um pouco maior, situando-se entre 12 e $15 \%$, podendo chegar até mesmo a $20 \%$ do total da população (ONU, 2002). ${ }^{2}$ No Brasil, ao longo da década de 1980, alguns municípios do estado de São Paulo realizaram pesquisas locais, que de um modo geral obtiveram resultados que confirmaram a estatística mundialmente aceita de 10\% (SASSAKI, 1998).

\footnotetext{
${ }^{2}$ Programa de Ação Mundial para as Pessoas com Deficiência ONU, 2002.
} 
Apesar de aceita no Brasil e no mundo, a estimativa de $10 \%$ utilizada sozinha não constitui uma base suficiente para avaliar a realidade e gravidade de algumas situações que envolvem a questão da deficiência, referindo-se às condições lastimáveis em que um grande número de pessoas vive e devido às inúmeras barreiras físicas e sociais que dificultam sua inclusão e participação na sociedade (SASSAKI, 1998). Além disso, a presença da deficiência repercute de maneira negativa em toda a população (ONU, 2002), dado o despreparo da sociedade em lidar com as diferenças.

No Brasil, o Instituto Brasileiro de Geografia e Estatística (IBGE), ao longo da última década do século XX, buscou a superação das dificuldades conceitualmetodológicas relativas à produção de dados sobre deficiências, tentando uma maior aproximação com a realidade. Isto foi constatado no último recenseamento da população brasileira realizado no ano de 2000, quando se percebeu que a finalidade da pesquisa não foi o conhecimento dos números relativos somente às deficiências, mas aos graus de severidade das incapacidades referentes às mesmas. Nesse Censo Demográfico foi adotado um conceito ampliado de deficiências, que incluiu a percepção que as pessoas pesquisadas têm em relação às alterações provocadas pela deficiência na sua capacidade de realização, de comportamento e de participação social (CORDE, 2004).

De forma coerente com essa nova orientação conceitual-metodológica, o Censo de 2000 analisou na amostra da população, a presença de pessoas com as seguintes deficiências: deficiência mental permanente; deficiência física permanente (tetraplegia, paraplegia, hemiplegia, falta de membro ou parte dele); e as deficiências visual, motora e auditiva, de acordo com o grau de incapacidade produzida ou limitação funcional, as quais possuem também subcategorias (SICORDE, 2002; IBGE, 2003). Na América Latina, o Brasil foi o primeiro país a utilizar essa classificação detalhada. ${ }^{3}$

${ }^{3}$ Censo 2000 Retrata Mudanças Sociais no Brasil. Matéria publicada no site http://www.

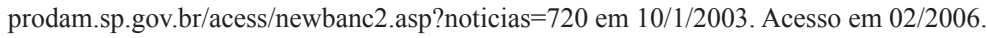




\section{FIGURA 1 - DEFICIÊNCIA NO BRASIL}

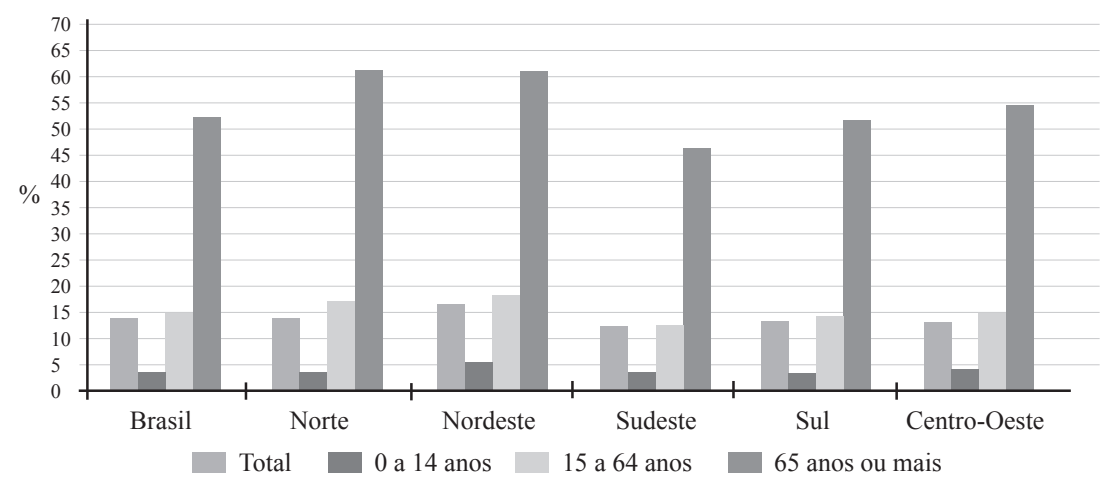

Proporção da população residente, possuidora de pelo menos uma das deficiências investigadas, por grandes grupos de idade, segundo as grandes regiões do Brasil - 2000.

FONTE: Adaptado do IBGE (2000)

No Censo anterior (1991), o percentual de pessoas com deficiência no Brasil era de 1,49\% sobre a população total. Já no Censo de 2000, dos 24,6 milhões de pessoas que declararam possuir alguma deficiência $(14,5 \%$ do total da população brasileira que era de 169,8 milhões em 2000), 4,3 eram crianças na faixa de idade entre 0 a 14 anos, o que pode ser verificado na Figura 1.

De acordo com a Figura 1, na Região Sul do país em 2000, a taxa encontrada com relação às pessoas com deficiência foi de $14,3 \%$ sobre a população total, e desse percentual, a faixa correspondente às crianças e adolescentes de 0 a 14 anos correspondia a 3,7\%. O estado de Santa Catarina apresentou um percentual de $14,21 \%$ com relação às deficiências em geral, sobre a população total do estado, situando-se entre os dez estados que possuem as menores taxas do país (IBGE, 2000). ${ }^{4}$

Com relação às deficiências apontadas no Censo 2000, observa-se um aumento expressivo com relação ao último Censo elaborado no ano de 1991 $(1,49 \%)$ no Brasil, sendo esse aumento mais significativo em relação às pessoas com deficiência visual. De acordo com a Figura 2, observa-se que a taxa brasileira de $14,5 \%$ de pessoas com deficiência divide-se em $1,24 \%$ de pessoas com deficiência mental, 0,59\% para deficiência física, 2,42\% para deficiência auditiva, $3,32 \%$ para deficiência motora e $6,97 \%$ para pessoas com deficiência visual.

\footnotetext{
${ }^{4}$ Baseado em informações do Censo do ano de 2000 do IBGE.
} 


\section{FIGURA 2 - PORCENTAGEM DAS DEFICIÊNCIAS}

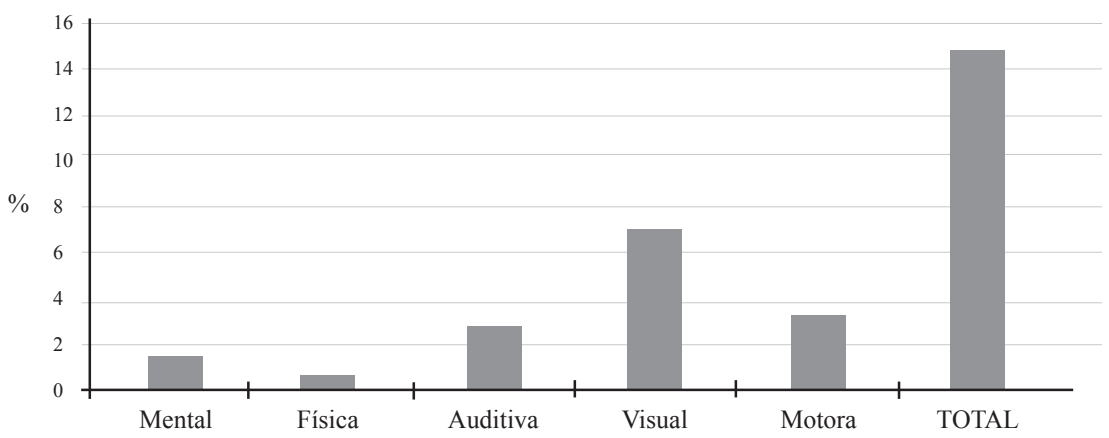

Tipo de Deficiência

Porcentagem de deficiências em relação à população brasileira.

FONTE: Adaptado do IBGE (2000)

Conforme o IBGE (2005), o percentual total de pessoas com deficiência no país não é muito diferente da taxa de outros países que utilizam os mesmos parâmetros do Brasil, como a Áustria (14,4\%), Espanha (15\%), Inglaterra $(12,2 \%)$ e Noruega (13\%) (IBGE, 2003). ${ }^{5}$ O que é comum, de maneira geral, para o grande contingente de pessoas com deficiência, é o que essa condição traz consigo: a pobreza, a segregação, a indiferença, a desigualdade de oportunidades e a exclusão (CPS/FGV, 2003).

O combate à pobreza e a desigualdade, por exemplo, deve passar pelo reconhecimento das diferenças, para impedir que estas se traduzam em desigualdades, visto que cerca de $41,62 \%$ dos indivíduos com percepção de incapacidades, ${ }^{6}$ vivem em situação de miséria (CPS/FGV, 2003). O não reconhecimento das diferenças transforma-se em exclusão, e isso já faz parte da história das sociedades. De certa forma, para reverter ou amenizar tais situações, é necessário que os diversos segmentos da sociedade (governo, profissionais das áreas de saúde, educação, profissionais responsáveis pelos projetos urbanísticos e de edificações, entre outros) se tornem colaboradores e partidários das ações em prol da inclusão das pessoas com deficiências. A inclusão é um processo que, de alguma forma, vem gradativamente ganhando força ao longo das últimas

5 Disponível em http://amaivos.uol.com.br/templates/amaivos/noticia/noticia.asp?cod_ noticia $=1794 \&$ cod_canal=42. Acesso em: 08/2006.

${ }^{6}$ Representam as pessoas com incapacidade de ouvir, de andar ou de enxergar, com deficiência física ou mental. (CPS/FGV, 2003) 
décadas, substituindo a prática da integração social, que há algum tempo tem ocupado o lugar da segregação e da exclusão das pessoas consideradas diferentes da maioria da população de qualquer sociedade, (SASSAKI, 1997).

\section{Números da deficiência na educação}

Um dos indicadores que permite apontar o nível educacional de uma população é a taxa de alfabetização e de analfabetismo; embora o número de pessoas alfabetizadas venha crescendo desde a década de 1950, a situação ainda não pode ser considerada ideal. A taxa de escolarização, que consiste na proporção de pessoas que freqüentam a escola, apresentou aumento expressivo, mas o número de crianças que ainda não freqüentam a escola é elevado em algumas regiões do país. Dados da Pesquisa Nacional por Amostra de Domicílios (PNAD) demonstram que o percentual de crianças de 7 a 14 anos fora da escola, em 2003, era de 2,8\%.

A estimativa do IBGE é de que em torno de 740 mil crianças brasileiras nessa faixa etária estejam fora da escola, considerando que esses números podem estar subestimados, pois a PNAD não inclui algumas áreas do país. Uma outra estimativa, considerando o Censo Demográfico do IBGE do ano de 2000, que abrange todo o país, apontou quase 1,5 milhões de crianças e adolescentes de 7 a 14 anos fora da escola.

Algumas circunstâncias como pobreza e deficiência podem prejudicar ou tornar a freqüência à escola inviável para algumas crianças e adolescentes no país, contribuindo para o processo de exclusão escolar. Pode-se constatar que a presença de uma deficiência contribui para o processo de exclusão na medida em que são analisados os dados do Censo Demográfico de 2000.

Entre os jovens com 15 anos ou mais, com pelo menos um tipo de deficiência, ainda segundo dados do IBGE, 32,9\% têm no máximo dois anos de escolaridade. Os outros índices relacionados a essa faixa etária demonstram que $16,7 \%$ têm entre 4 e 7 anos de estudo; 10,7\%, entre 8 e 10 anos de escolaridade; $10 \%$, entre 11 e 14 anos; e 10,2\% têm 16 anos ou mais. Esses dados indicam que praticamente um terço da população com deficiência e em idade de entrar no mercado de trabalho tem, no máximo, dois anos de estudo, um quadro que precisará ser revertido para que as pessoas com deficiência possam incluir-se efetivamente na sociedade, ocupando os cargos reservados para elas por lei nas empresas (CLARO, 2003). 
Segundo estudo da Fundação Getúlio Vargas, observou-se também que a escolaridade média das pessoas que possuem alguma deficiência é menor que aquelas que não a possuem. As taxas correspondentes às pessoas que nunca freqüentaram a escola são de $16,3 \%$ para a população em geral, de $21,6 \%$ para as pessoas com deficiência, e de $33,7 \%$ para as pessoas que têm percepção de incapacidade (CPS/FGV, 2003).

Quando se analisa a situação dos alunos com deficiência em relação à população geral, verifica-se que sua participação é muito baixa quando comparada ao restante da população, mesmo atestando-se que esta também enfrenta problemas, em alguns aspectos, semelhantes aos alunos com deficiência. Pode-se concluir, que na grande maioria das análises dos números da deficiência nas escolas, a taxa de não participação e de abandono é muito mais alta para as pessoas com algum tipo de limitação física ou sensorial, além de comprovar que o tempo que os alunos com restrições permanecem na escola é muito curto (LOCH, 2006).

Esses dados enfatizam a necessidade de educação para as pessoas com deficiência, demonstrando o baixo índice de freqüência destes desde a fase escolar primaria até a educação superior. Por outro lado, quando se considera a educação de adultos, esses números aumentam significativamente, além de retratarem o atraso nos estudos desse grupo. Tais dados tornam bem clara a realidade das pessoas com deficiência, que ao se depararem com o mercado de trabalho, são obrigadas a freqüentar supletivos e/ou outro tipo de educação não seriada. Se essas pessoas encontram condições de aprendizado quando adultas, certamente teriam tido condições de aprenderem quando crianças (LOCH, 2006).

$\mathrm{Na}$ Figura 3 observa-se que o percentual de crianças de 7 a 14 anos sem acesso à escola, que era de 5,5\% (2000) em todo o Brasil, sobe para 11,4\% se forem consideradas somente as crianças que possuem alguma deficiência. Esse quadro é ainda mais preocupante (39\%) se forem consideradas só as crianças com paralisia ou falta de algum membro. De acordo com os dados apresentados pelo Censo do IBGE em 2000, pelo menos 179 mil crianças brasileiras que possuíam alguma deficiência, não estavam nas escolas e se encontravam privadas de seu direito ao ensino fundamental (UNICEF, 2005). 
FIGURA 3 - CRIANÇAS FORA DA ESCOLA

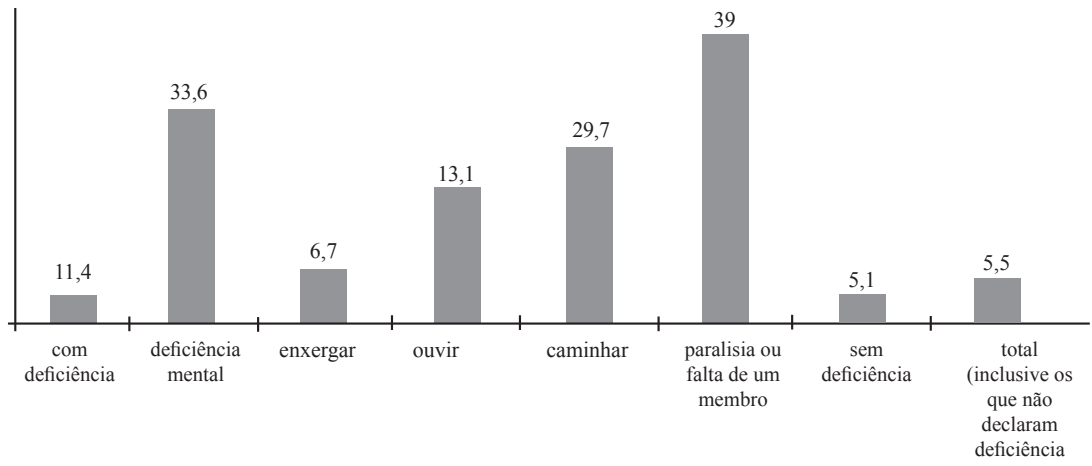

Tipo de Deficiência

Percentual de crianças de 7 a 14 anos fora da escola em 2000 no Brasil

FONTE: UNICEF (2005)

O Censo Escolar divulgado pelo INEP anualmente indicou no ano de 2005 um total de 640.317 alunos com deficiência matriculados em escolas especiais e/ou classes especiais e escolas regulares e/ou classes comuns do sistema de ensino brasileiro (Figura 4). Entre esses alunos, 278.167 possuem deficiência mental, 67.191 possuem deficiência múltipla, 66.314 possuem deficiência auditiva (surdez e deficiência auditiva) e 63.631 possuem deficiência visual.

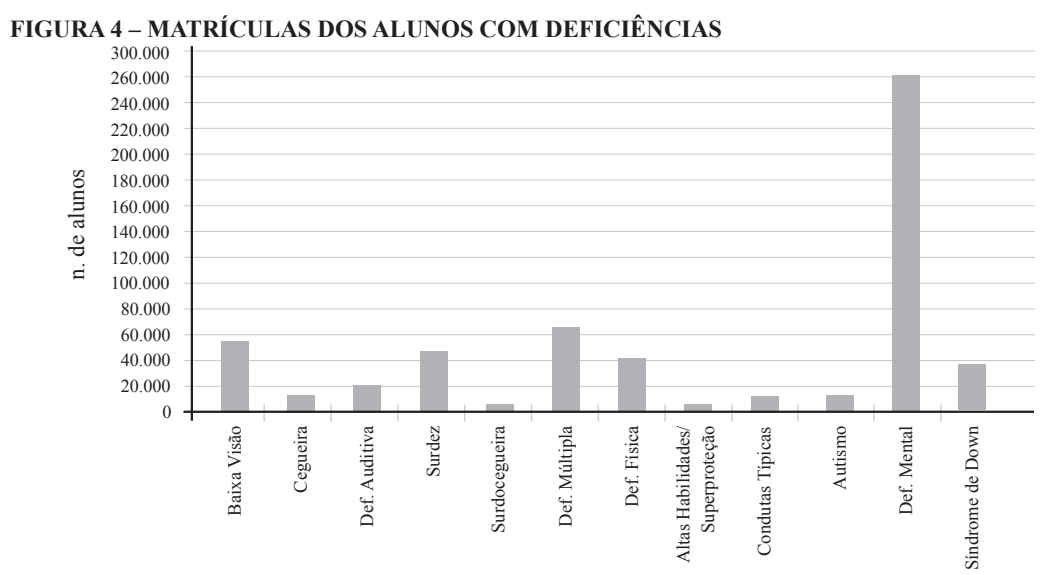

Número de alunos com deficiências matriculados no sistema de ensino brasileiro

Fonte: INEP (2005) 
Nos últimos anos, o Censo Escolar elaborado pelo INEP tem demonstrado uma tendência na queda de matrículas de alunos com deficiências nas escolas especiais, e, ao mesmo tempo, é constatado o aumento de matrículas desses alunos na rede de escolas regulares, com ou sem apoio pedagógico especializado (INEP, 2005). ${ }^{7}$ Essa diminuição vem sendo constatada desde o ano de 1988 até o último Censo Escolar divulgado (2005). Os dados indicaram ainda que nas escolas especiais o número de alunos matriculados chegava a $64 \%$ em 2005, considerando-se o número total de alunos com deficiências (640.317), enquanto que nas escolas de ensino regular esse percentual, que era de $13 \%$ em 1998 , chegou a 41\% no ano de 2005 (MEC/SEESP, 2006).

Observa-se que o número de alunos com deficiência matriculados na rede de escolas especiais e regulares no ano de 2005 na Região Sul obedece à tendência do país, mas em percentual menor na rede regular (30,2\%), e maior com relação às escolas especiais $(69,8 \%)$, levando-se em consideração o índice nacional (MEC/SEESP, 2006). Outra tendência verificada no país é a diminuição das matrículas dos alunos com deficiências na rede privada de ensino, ao mesmo tempo em que a rede pública tem um crescimento no número de matrículas do ano de 2002 até o ano de 2005. O Censo Escolar elaborado pelo INEP entre os anos de 1998 e 2005 indicou que, no Brasil, além de superar a esfera privada em número de matrículas a partir de 2002, as escolas públicas em 2005 já concentravam $60 \%$ dos alunos com necessidades de apoio pedagógico especializado.

\section{Números do Ensino Fundamental}

O ensino fundamental tem a freqüência obrigatória para todas as crianças, inclusive para aquelas que necessitam de apoio pedagógico especializado durante a permanência na escola, segundo a Lei de Diretrizes e Bases da Educação (LDBEN, 1996). No Brasil, atualmente, a queda nas matrículas referentes ao ensino fundamental é percebida em todo o país, diminuindo de 35,15 milhões em 2002 para 34,72 milhões em 2003, 1,41\% em 2005 com relação a 2004. Essa tendência ocorre desde 1998, e uma das causas é o novo entendimento a partir da LDBEN a respeito da educação, avaliação e reprovação. Conforme os estudos do INEP, a tendência de queda deve

${ }^{7}$ A partir de dados fornecidos pelo Censo Escolar do INEP, disponíveis no site http://www. inep.gov.br/basica/censo/Escolar/Sinopse/sinopse.asp. Acesso em 03/2006. 
manter-se nos próximos anos, de acordo com projeções referentes ao número de matrículas nesse nível até o ano de 2011 (INEP, 2005). ${ }^{8}$

Com relação aos alunos com deficiência matriculados no ensino fundamental em escolas públicas e particulares, no ano de 2004, estes somavam 535.367 estudantes, e a maior parte recebia atendimento na rede pública de ensino, sendo exceção de acordo com os dados do INEP os estudantes com deficiências mentais, deficiência múltipla e surdez. Analisando-se os dados, percebe-se que nos anos de 2003, 2004 e 2005 houve um aumento significativo das matrículas dos alunos com deficiências, com uma ampliação na esfera pública. Além de superar a esfera privada em número de matrículas a partir do ano de 2002, as escolas públicas em 2004 já concentravam $57,7 \%$ desses alunos (INEP, 2005) ${ }^{9}$.

No estado de Santa Catarina, em 2005, ao contrário da tendência nacional, o número de alunos com deficiências matriculados na rede regular de ensino diminuiu em torno de $8 \%$, com um decréscimo de $9,42 \%$ de alunos inscritos na rede pública e um aumento de $14,7 \%$ na rede privada. Em Florianópolis, a distribuição desses alunos (num total de 213) nas escolas regulares na cidade, no ano de 2004, era de cerca de $84 \%$ na rede pública e em torno de $15 \%$ na rede particular de ensino. No ano de 2005 esse índice aumentou em $14 \%$, sendo que a distribuição dos estudantes na rede pública e privada permaneceu praticamente como no ano de $2004 .{ }^{10}$

\section{Conclusão}

Segundo o Ministério da Educação (MEC), os desafios de promover no Brasil uma escola pública inclusiva e de qualidade vêm apresentando bons resultados, o que também é constatado por meio dos dados levantados pelo Censo Escolar. Embora exista um movimento para estimular a inclusão dos alunos que possuem alguma deficiência nas escolas públicas regulares, e que a tendência seja atender, a cada ano, um número maior de alunos, e que seja constatado o aumento progressivo de alunos matriculados em regime de inclusão nas escolas públicas do Brasil, existem ainda muitas crianças que não freqüentam à escola, devido a falta de condições para sua permanência.

\footnotetext{
${ }^{8}$ Matéria publicada no dia 8 de setembro de 2004 no site http://www.inep.gov.br/imprensa/ noticias/outras/news04_41.htm. Acesso em 02/2006.

${ }^{9}$ A partir de dados fornecidos pelo Censo Escolar do INEP, disponíveis no site http://www. inep.gov.br/basica/censo/Escolar/Sinopse/sinopse.asp. Acesso em 03/2006.

10 A partir de dados fornecidos pelo Censo Escolar do INEP, disponíveis no site http://www. inep.gov.br/basica/censo/Escolar/Sinopse/sinopse.asp. Acesso em 03/2006.
} 
Analisando-se os dados e comparando-os com o número de crianças apontadas pelo último Censo populacional do país, é possível verificar que muitas delas ainda estão fora das escolas, sejam estas inclusivas ou não. Esse fato constata que o processo de inclusão dos alunos com deficiências no sistema regular de ensino precisa ser consolidado, e ainda possui um caminho a ser trilhado. Neste sentido, os esforços devem ser ampliados em direção à inclusão, pois as condições reais não são ainda as ideais; de acordo com Mittler (2001), as crianças com restrições que ainda não freqüentam a escola geralmente levam uma vida solitária e isolada sociedade.

Os números relacionados ao longo do artigo reforçam a necessidade do ensino de qualidade para crianças com deficiências. Destaca-se o fato de esse fracasso e evasão escolar estarem diretamente ligados ao despreparo das escolas em receber e atender essas crianças. Essa realidade pode ser modificada se as escolas estivessem preparadas para lidar com as diferenças, respeitá-las e ultrapassá-las, fazendo delas parte de suas rotinas, sem privilegiar um ou outro aluno. Oferecer ensino básico de qualidade para todos, com ou sem deficiências, significa melhorar a qualificação e dar condições de tais crianças, quando adultas, competirem no mercado de trabalho ( $\mathrm{LOCH}, 2006$ ).

\section{REFERÊNCIAS}

BRASIL. Ministério da Educação. Lei n. 9.394, de 20 de dezembro de 1996. Lei de Diretrizes e Bases da Educação Nacional (LDBEN). Diário Oficial da União, n. 248, de 23/12/1996. Brasília: MEC, 1996.

BRASIL. Ministério da Educação e Cultura. SEESP. Números da educação especial no Brasil. Brasília, 2005. Disponível em <http://portal.mec.gov.br/seesp/index.php?o ption $=$ content\&task=view\&id=62\&Itemid=191 $>$. Acesso em: 23/5/2006.

BRASIL. Ministério da Educação e Cultura. SEESP. Números da educação especial no Brasil. Brasília, 2006. Disponível em: <http://portal.mec.gov.br/seesp/index.php? option $=$ content\&task=view\&id=62\&Itemid=191>. Acesso em: 30/5/2006.

CLARO, C. Recursos educacionais: como estimular o processo de aprendizagem das pessoas com deficiência. 2003. Disponível em <http://www.tele-centros.org/ discapacitados $/ \mathrm{secao}=103 \&$ idioma $=$ br.html $>$. Acesso em: 3/5/2005.

CPS/FGV. Diversidade: retratos da deficiência no Brasil. Fundação Getulio Vargas e Fundação Banco do Brasil, 2003. Disponível em <http://www.fgv.br/cps/deficiencia_br/ index 2.htm>. Acesso em: 30/3/2005. 
COORDENADORIANACIONALPARAINTEGRAÇÃO DAPESSOAPORTADORA DE DEFICIÊNCIA (CORDE). Relatório sobre a prevalência de deficiências, incapacidades e desvantagens. Brasília: CORDE, 2004.

INEP. Censo Escolar do INEP. 2005. Disponível em: <http://www.inep.gov.br/basica/ censo/Escolar/Sinopse/sinopse.asp >. Acesso em: 30/3/2006.

LOCH, M. V. P. Arquitetura inclusiva escolar condizente com a prática pedagógica construtivista. Qualificação (Doutorado em Engenharia de Produção) - Departamento de Pós-graduação de Engenharia de Produção e Sistemas, Universidade Federal de Santa Catarina, Florianópolis, 2006.

MITTLER, P. Educação de necessidades especiais: uma perspectiva internacional. In: SEMINÁRIO INTERNACIONAL SOCIEDADE INCLUSIVA PUC MINAS. Anais... Belo Horizonte: PUC Minas, 2001.

ONU. Programa de ação mundial para as pessoas com deficiência. ONU, 2002. Disponível em: <http://www.interlegis.gov.br/processo_legislativo/copy_of_200203 19150524/20030623133227/20030623114443/view>. Acesso em: 24/8/2006.

SASSAKI, R. K. Inclusão social: o novo paradigma para todos os grupos minoritários. 1997. Disponível em: <http://www.entreamigos.com.br>. Acesso em: 5/10/2005.

. Quantas pessoas têm deficiência? 1998. Disponível em: <http://www. educacaoonline.pro.br/art_quantas_pessoas_tem_deficiencia.asp?f_id_artigo $=65>$. Acesso em: 23/12/2005.

SICORDE. Sistema Nacional de Informações sobre Deficiência. Estudos censitários. 2005. Disponível em: <http://www.mj.gov.br/sedh/ct/corde/dpdh/sicorde/default. asp\#conteudo>. Acesso em: 30/5/2005.

UNICEF. Situação mundial da infância. UNICEF, 2005. Disponível em: $<$ http://www. unicef.org/brazil/sowc05/main.htm>. Acesso em: 25/1/2006.

Texto recebido em 14 dez. 2006 Texto aprovado em 23 mar. 2007 